\title{
Restless leg syndrome: is it a real problem?
}

\author{
Paul E Cotter \\ Shaun T O'Keeffe \\ Department of Geriatric Medicine, \\ Galway University Hospitals, Galway, \\ Ireland
}

\begin{abstract}
Restless legs syndrome (RLS) is a common condition that is frequently unrecognized, misdiagnosed and poorly managed. It is characterized by uncomfortable sensations deep in the legs developing at rest that compel the person to move; symptoms are worst at night and sleep disturbance is common. RLS occurs in $7 \%-11 \%$ of the population in Western countries, and many such people experience troublesome symptoms. Primary RLS is familial in up to two thirds of patients. RLS may also be secondary to a number of conditions including iron deficiency, pregnancy and end-stage renal failure and, perhaps, neuropathy. Secondary RLS is most common in those presenting for the first time in later life. The pathogenesis of RLS probably involves the interplay of systemic or brain iron deficiency and impaired dopaminergic neurotransmission in the subcortex of the brain. RLS is very responsive to dopaminergic therapies. Rebound of RLS symptoms during the early morning and development of severe symptoms earlier in the day (augmentation) are problematic in those treated for a prolonged period with levodopa. Consequently, dopamine agonists have become first line treatment. Anti-convulsant medications and opioids are helpful in some patients. Correction of underlying problem wherever possible is important in the management of secondary RLS.
\end{abstract}

Keywords: Restless legs syndrome; sleep; iron deficiency; neuropathy

\section{Introduction}

Restless Legs Syndrome (RLS) was first described in the medical literature by the anatomist and physician Thomas Willis in 1685 and has been recognized as a welldefined, common and frequently distressing entity since Ekbom's classic description in 1945. Nevertheless, RLS has attracted little attention in medical textbooks until recently, and, even now, it is often unrecognized, misdiagnosed and poorly managed.

In this paper, we explore the reasons for the relative neglect of RLS, explain current thinking regarding the pathogenesis and management of the condition and show why patients with RLS will benefit from careful investigation and treatment.

\section{What is RLS?}

RLS is both a sensorimotor and a sleep disorder. It is characterized by unusual, uncomfortable sensations deep in the legs (and sometimes arms) that compel the person to move to relieve the sensation and that are brought on and exacerbated by rest; symptoms are particularly troublesome in the evening and at night, and sleep disturbance is common. The original report by Willis (1685) described the motor features and the sleep disruption but did not mention the sensory features that are often the main complaint of patients. In contrast, Karl-Axel Ekbom (1945) emphasized the importance of the sensory component of the condition.

The current diagnostic criteria were developed at an National Institutes of Health (NIH)-supported workgroup on RLS and represent a slight modification of the original diagnostic criteria published by the International RLS Study Group in 1995 (Walters 1995; Allen et al 2003). There are four essential criteria and three supportive clinical features (Table 1). 
The sensation is deep seated, often described as being in the shin bones, and most commonly felt between the knee and ankle. It may be described as a creepy, crawly, shocklike, tense, electric, buzzing, itchy, or even numb sensation. Bizarre analogies may be draw such as 'worms under the skin' or 'cola in the veins'. There is a variable response to temperature, with some finding heat an aggravating factor and removing the bedclothes, whilst others find that wearing socks or taking a hot bath improves symptoms.

RLS patients not only feel an urge to move but, while this may be resisted for a time, they must at some stage actually yield to the urge and move the legs. This movement should lead to immediate, even if sometimes only partial, relief that persists while moving. Mild cases can get relief from rubbing the legs or stretching them in the bed, but people with more severe symptoms need to get out of bed and walk, or stretch, or march on the spot.

There is always a strong circadian pattern to symptoms in RLS. The peak is usually during the earlier part of the night, but the precise timing will vary depending on the sleep habits and the trough of circadian rhythm for the individual. The rest-induced and circadian patterns of RLS can be distinguished. Thus, symptoms during rest at night are worse than symptoms at rest during the day.

There are a number of conditions that may be confused with RLS. Akathisia is a closely related condition that shares the sense of restlessness, the inability to sit still and, less prominently, the sleep disturbances (Walters et al 1991). However, the restlessness is generalized and internal rather than localized to the limbs and associated with paresthesias.
The history of exposure to neuroleptic medications and associated extrapyramidal features also differentiate akathisia from RLS. Nocturnal leg cramps are characterized by episodes of pain, usually lasting up to a few minutes, caused by sudden, intense involuntary contractions of muscles or muscle groups. Residual discomfort and tenderness may persist for hours afterwards. They should be readily distinguishable from RLS by history alone. Polyneuropathy may lead to symptoms of burning in the legs and feet at night. However, there is no restlessness and no improvement with movement. Also, physical examination in these cases will reveal a sensory and occasionally motor deficit. Peripheral vascular disease can result in rest pain at night, which should be readily identifiable; clinical examination may demonstrate ischaemic features in the leg. Painful legs and moving toes is an uncommon condition associated with involuntary toe movements and with pain in the legs that has a similar distribution to that seen in RLS (Dressler et al, 1994). The major difference is that the pain in the former is not relieved by movement.

\section{Why is RLS neglected?}

RLS is often unrecognized or misdiagnosed. In a study published in 1996 of patients who belonged to the 'Night Walkers' support group, patients delayed seeking attention for many years, but even after they sought medical help, accurate diagnosis frequently took a decade or more (Walters et al 1996). The expansion in knowledge and the increased publicity about the condition in recent years seems to have

Table I Features of restless legs syndrome (RLS). Modified from Allen RP, Picchietti D, Hening WA, et al. 2003. Restless legs syndrome: diagnostic criteria, special considerations, and epidemiology. A report from the restless legs syndrome diagnosis and epidemiology workshop at the National Institutes of Health. Sleep Med Mar, 4:101-19.

A. Essential criteria:These features must be present for a diagnosis of RLS.

I. An urge to move the legs, usually accompanied or caused by uncomfortable or unpleasant sensations in the legs. (Sometimes the urge to move is present without the uncomfortable sensations and sometimes the arms or other body parts are involved in addition to the legs.)

2 The urge to move or unpleasant sensations begin or worsen during periods of rest or inactivity such as lying or sitting.

3. The urge to move or unpleasant sensations are partially or totally relieved by movement, such as walking or stretching, at least as long as the activity continues.

4. The urge to move or unpleasant sensations are worse in the evening or night than during the day or only occur in the evening or night. (When the symptoms are very severe, the worsening at night may not be noticeable, but must have been previously present.)

B. Supportive clinical features of RLS: Presence of these features may help resolve any diagnostic uncertainty.

I. Periodic limb movements (during wakefulness or sleep).

2 Family history of RLS in a first degree relative.

3. Response to dopaminergic therapy.

\section{C.Associated clinical features:These features may provide additional information about the patient's diagnosis.}

I. Clinical course following certain identifiable patterns.

2 Sleep disturbance.

3. Normal medical evaluation/ physical examination. 
made little difference and has led to accusations of 'disease mongering' (Woloshin and Schwartz 2006). An international population study published in 2004 reported that two thirds of those with weekly RLS symptoms said that they had spoken to a physician about their symptoms and only $8 \%$ said that they had received a diagnosis of RLS (Hening et al 2004). A number of myths and misconceptions probably contribute to this dismal situation.

\section{Myth I: RLS is a trivial condition}

RLS is sometimes regarded as merely an inconvenience to the sufferer or even as an entity with no physiological basis. A number of factors may underlie this myth. The very name of the condition sounds benign if not even slightly funny. Few of us have not experienced the discomfort and urge to move the legs that develops on a long, cramped journey, and RLS may be regarded as a 'natural' phenomenon. Clinicians may be sceptical, in particular, of the high prevalence of RLS reported in epidemiological studies.

It is important to acknowledge that many people with RLS have relatively mild symptoms, and it is doubtful whether there is any benefit in telling such people that they have a recognized medical condition. Nevertheless, there is a substantial group of patients with symptoms of sufficient severity to warrant intervention. Data from the RLS Epidemiology, Symptoms and Treatment (REST) studies conducted in the general population and in primary care practices in the US and some European countries illuminate this point (Hening et al 2004; Allen et al 2005). RLS of any degree of frequency or severity occurred in $7.2 \%$ and $11.1 \%$ of these studies respectively; RLS that occurred more than twice a week and that caused significant distress was present in roughly a third of each group (2.7\% and $3.4 \%$ respectively). Also, even those with mild symptoms may benefit from being given a diagnosis to explain their unusual symptoms.

It is also true that RLS does not pose the same threat to health as does heart disease or diabetes, for example. Nevertheless, as will be shown later, it may have a very significant effect on the quality of life of the sufferer, and the chronic insomnia in particular may impact on daytime functioning.

\section{Myth 2: RLS is 'all in the head'}

Many sufferers report that they have been told their symptoms are psychogenic. Richard Allen (personal communication) tells of one patient who was referred for five years of psychoanalysis as doctors were convinced that he was kicking his wife at night because he was angry at his mother! The difficulty that RLS patients often experience in describing the nature of their leg sensations, and the sometimes bizarre analogies they draw, may contribute this misconception. Patients may also delay presenting for medical attention because they fear they will not be believed.

It is undeniable that RLS is associated with anxiety and depression (Picchietti and Winkelman 2005). In a study from Munich, RLS patients were compared with patients with other chronic disorders (Winkelmann et al 2005). There was a much higher prevalence in the RLS group of panic disorder (odds ratio [OR] of 4.7), of generalized anxiety disorder (OR 3.6) and of major depression (OR 2.7). Also, the RLS patients were more likely to attribute their psychiatric disorders and associated symptoms directly to the impact of their underlying condition on their life. The association with depression also has practical significance for the management of RLS; serotonin reuptake blocking antidepressants and, less often tricyclic antidepressants, can precipitate or exacerbate symptoms of RLS (Dorsey et al 1996). Bupropion, an antidepressant with dopamine agonist activity, may be a useful alternative (Nofzinger et al 2000).

\section{Myth 3: RLS is 'all in the legs'}

The notion that RLS is due to a vascular disorder of the legs, especially of the veins, dates back to Ekbom (1945) and persists to some degree today (Kanter 1995). Examination of peripheral arteries and veins is normal in most RLS patients. Procedures to reduce incompetent veins have not been shown to reduce RLS symptoms (Kanter 1995; Bradbury et al 1999).

The role of peripheral neuropathy in the pathogenesis of RLS is less clear cut. It has been reported that RLS may be a presenting feature of neuropathy, such as those due to diabetes mellitus, alcohol abuse, Charcot-Marie-Tooth syndrome type 2, and of spinal disease such as radiculopathy (Ondo and Jankovic 1996; Gemignani et al 1999). Also, detailed evaluation of RLS patients with sural nerve or skin biopsies has found a high frequency of clinically undetectable axonal and small-fiber neuropathies (Polydekis et al 2000). However, other studies have suggested that the frequency of RLS in neuropathic patients is similar to that in the general population (Salih et al 1994; Banno et al 2000). Nevertheless, as will be discussed later, most evidence points to a central nervous system abnormality. 


\section{Myth 4: There is no good treatment for RLS}

A degree of therapeutic nihilism may have been justified in the past but is inexcusable with the emergence, in particular, of dopaminergic treatments for RLS. Unfortunately, many clinicians persist in using benzodiazepines, which, while sometimes effective, often cause unacceptable side effects. Others, perhaps misdiagnosing RLS as related to muscle cramps, use quinine, which has been shown to be ineffective in RLS (Van Dijk et al 1991).

\section{Why is RLS an important condition?}

RLS is an important condition because it is common, it causes significant distress to sufferers, it may be the presenting feature of serious underlying conditions and it is treatable. In recent years, there has been an improved understanding of the pathophysiology of the condition, particularly in relation to genetic susceptibility and to the importance of dopamine and of iron metabolism.

\section{RLS is common}

Ekbom performed the first study on the prevalence of RLS and reported that about $5 \%$ of a middle aged Swedish population had the condition (Ekbom 1945). However, interpretation of this and subsequent studies up to 1995 were hampered by the lack of agreed diagnostic criteria for the condition. Since then a substantial number of studies have been conducted, mainly in European and North American populations, using questions designed to elicit the essential criteria of the condition and usually requiring some minimum frequency of symptoms. As a general rule, slightly higher rates are found in studies based on self-administered questionnaires compared with studies using face-to-face or telephone interviews; the latter studies are probably more reliable. Allowing for differences in study designs and in the age and sex profile of the populations studied, there has been a remarkable consistency across different studies, with prevalence rates ranging from approximately $5 \%$ to $15 \%$. Indeed more recent studies have converged on a range of $7 \%-11 \%$. For example, a large recent French study, involving face-to-face interviews of 10238 individuals, found a prevalence of RLS symptoms of $8.5 \%$ with a narrow confidence interval of $\pm 0.5 \%$ (Tison et al 2005) (Table 2).

An increase in symptoms with age has been reported in most studies. For example, in an American study, Phillips and colleagues (2000) asked 1803 men and women on the telephone if they experienced symptoms of restless legs 5 or more nights per month. They received a positive response in $3 \%$ of participants aged 18 to $29,10 \%$ aged 30 to 79 years and $19 \%$ of those aged 80 years and older. In recent years, there is increased recognition that RLS may also present during childhood; the condition may be misdiagnosed as attention-deficit/hyperactivity disorder or as 'growing pains' (Kotagal and Silber 1999).

Another striking finding, originally reported by Ekbom (1945), is the increased frequency of the condition in women compared with men, with a two-fold difference in some reports (Rothdach et al 2000; Egan et al 2003). Associations that have been reported in population studies include links to psychiatric disorders, general health, smoking, body mass index, lower socioeconomic status, diabetes, lack of exercise, and alcohol abstinence (Phillips et al 2000).

The relatively few studies in non-European populations suggest that RLS may be less common in such populations. A Turkish study found a prevalence of $3 \%$, while a study in Singapore found that less than $1 \%$ of those questioned reported RLS symptoms (Sevim et al 2003). A Japanese study found that $1.1 \%$ reported RLS symptoms; however, contrary to the pattern in Europe, symptoms were more common in men. On the other hand, a recent Korean study

Table 2 Epidemiological studies of the prevalence of Restless Legs Syndrome using International Restless Legs Syndrome (IRLS) Study Group criteria and either telephone or face-toface interviews

\begin{tabular}{|c|c|c|c|c|}
\hline Year & Author & $\mathbf{n}$ & Population & Prevalence \\
\hline 1994 & $\begin{array}{l}\text { Lavigne and } \\
\text { Montplaisir }\end{array}$ & 2019 & Canada, & $10 \%$ \\
\hline 2000 & Phillips et $\mathrm{al}^{* *}$ & 1803 & Kentucky, USA & $10.0 \%$ \\
\hline 2000 & Rothdach et al & 369 & $\begin{array}{l}\text { Germany, } \\
65-83 \text { years }\end{array}$ & $9.8 \%$ \\
\hline 2002 & $\begin{array}{l}\text { Ohayon and } \\
\text { Roth }\end{array}$ & 18980 & $\begin{array}{l}\text { Five European } \\
\text { countries }\end{array}$ & $5.5 \%$ \\
\hline 2003 & Sevim et al & 3234 & Turkey, & $3.2 \%$ \\
\hline 2005 & Allen et al & 15391 & $\begin{array}{l}\text { USA, } 5 \text { European } \\
\text { countries, }\end{array}$ & $7.2 \%$ \\
\hline 2005 & Högl et al & 701 & $\begin{array}{l}\text { Bruneck, } \\
\text { Northern Italy, } \\
40-79 \text { y }\end{array}$ & $10.6 \%$ \\
\hline 2005 & Bjorvatn et al & 2005 & $\begin{array}{l}\text { Norway and } \\
\text { Denmark, }\end{array}$ & $11.5 \%$ \\
\hline 2005 & Mizuno et $\mathrm{al}^{\dagger}$ & 3287 & Japan $>65$ years & $1.1 \%$ \\
\hline 2005 & Tison et al & 10263 & France, adults & $8.5 \%$ \\
\hline 2005 & Kim et al & 9930 & Korea, adults & $12.1 \%$ \\
\hline
\end{tabular}

Notes: * 3 of 4 IRLS criteria used for diagnosis; ${ }^{* *} 2$ of 4 IRLS criteria used for diagnosis; ${ }^{\dagger}$ Screening by questionnaire, followed by telephone interview. 
reported RLS in $12 \%$ of those studied and found a higher prevalence in women and in older people (Kim et al 2005).

\section{RLS can cause significant distress}

Severe RLS is a deeply unpleasant condition. In a study of the impact on quality of life of sufferers (using the Short Form-36 Health Survey), RLS had a similar effect to other chronic disorders, such as type 2 diabetes, and clinical depression (Allen et al 2005). RLS may require a considerable restriction of lifestyle as a result of intolerable symptoms during long airplane or car journeys, lectures or visits to the cinema.

One or more aspects of the condition may be particularly troublesome for individual patients. As part of the REST primary care study, 182 patients with RLS were asked about their symptoms (Hening et al 2004). The most troublesome symptoms reported were sleep disturbance (39\%), followed by uncomfortable feelings in the legs $(27 \%)$, pain $(22 \%)$ and inability to stay still and urge to move the legs (11\%).

Thus, sleep disturbance, subsequently causing disturbance of day-time functioning in many, are of particular significance to RLS patients. This is not surprising since severe RLS produces the most extreme chronic sleep loss of any sleep disorder. There are multiple reasons for this. In the REST study, almost $70 \%$ of sufferers reported a sleep latency (the time to get to sleep) of 30 minutes or longer, which is considered to be in the insomnia range. On a poor night, $50 \%$ reported less than 5 hours sleep and $14 \%$ got less than 3 hours sleep. Almost $60 \%$ reported that they wake three or more times a night so that sleep is significantly fragmented. Other daytime symptoms reported by patients included fatigue in $60 \%$ and difficulty concentrating in $50 \%$. However, RLS patients do not report the same degree of daytime sleepiness or the risk of accidents that have been found, for example, in the sleep apnoea population. This may be due to the restlessness, with arousal and activity, intrinsic to the condition.

The fragmentation of sleep may result from the RLS itself or from accompanying periodic limb movements of sleep (PLMS) (Trenkwalder, Walters, et al 1996). PLMS are semirhythmic movements of the limbs which last a few seconds and occur at regular intervals. The most frequent movement seen is dorsiflexion of the great toe (similar to the Babinski response), with flexion of the knee, hip, and occasionally elbow. PLMS can occur in otherwise healthy people and are especially common in old age. In RLS, they are almost always present, are often very intense and can cause arousals and awakenings. Some RLS patients do not get symptoms until they have been asleep for a while; they wake up, perhaps because of the PLMS, and develop the fidgety sensations of RLS and have to get up and walk for a while before they can return to sleep.

RLS is a chronic disorder. In the Hopkins family study, the average duration of symptoms in 66 RLS patients was 30 years $(n=66)$ (Allen et al 2002). In general, symptoms tend to progress with advancing age, although there is considerable individual variability.

\section{RLS may be symptomatic of an underlying condition}

RLS can generally be divided into primary and secondary forms. RLS is primary (idiopathic) in most cases, and up to half of these patients have a positive family history (Trenkwalder, Seidel, et al 1996). RLS may also develop secondary to a variety of conditions, although, since RLS is a common condition, many of the associations suggested by case reports remain unproven. Secondary causes of RLS are more common in those who develop the condition for the first time in later life, occurring in over $70 \%$ of those with onset at 65 years or more, while a positive family seems most common those with early-onset RLS (O'Keeffe 2005).

\section{Genetics of RLS}

The mode of inheritance of RLS seems to be autosomal dominant. There is a high concordance rate $(83 \%)$ for RLS symptoms in monozygotic twins (Ondo et al 2002) although expression of RLS can vary between twins and within families. Age-dependent penetrance of RLS has been reported, with full penetrance by the age of 60 (Winkelmann 2002). Anticipation, an earlier age of onset in later generations, has also been reported (Trenkwalder, Seidel, et al 1996). Susceptibility loci have been described on chromosome $12 \mathrm{q}$ in a French-Canadian family (Desaultels et al 2001), on chromosome 14q in an Italian family (Bonati et al 2003) and on chromosome 9p in North American families (Chen et al 2004). It seems increasingly likely that multiple genes influence the development of RLS, perhaps interacting with environmental factors.

\section{Secondary RLS}

The most important secondary form of RLS is the association with iron deficiency (with or without anemia) which is present in up to a third of RLS patients (Ekbom 1960; O'Keeffe et al 1993), including those presenting in childhood pains (Kotagal and Silber 1999). Serum ferritin is accepted as the best screening test for iron deficiency, 
and in older hospital patients, the diagnosis of iron deficiency is almost certain in those with ferritin less than $20 \mathrm{ng} / \mathrm{mL}$ and is likely in those with levels less than $50 \mathrm{ng} /$ $\mathrm{mL}$. The severity of RLS symptoms correlates well with the serum ferritin level, even in patients who are not obviously iron deficient and who have normal hemoglobin and MCV levels (O'Keeffe et al 1994). A search for an underlying cause of iron deficiency is usually indicated and may lead to the detection of new cancers (Brocklehurst 2003; O'Keeffe 2005).

RLS has been noted in $15 \%$ to $40 \%$ of patients with end-stage renal disease; it is particularly prominent in patients on hemodialysis, possibly because of the enforced rest (Collado-Seidel et al 1998). RLS is also common during the third trimester of pregnancy and resolves after delivery (Lee et al 2001). Development of transient RLS during pregnancy may suggest a predisposition to develop the condition in later life (Ulfberg et al 2001; Berger et al 2004). There is also good evidence to support associations between RLS and rheumatoid arthritis and Sjogren's syndrome (Reynolds et al 1986; Gudbjornsson et al 1993; Salih et al 1994). As was noted earlier, the relationship between RLS and peripheral neuropathy is unclear. There have also been conflicting reports regarding a possible association between RLS and Parkinson's disease (PD) are associated (GarciaBorreguero et al 2003). A recent study noted that $21 \%$ of PD patients had RLS, with lower ferritin levels being the main predicting factor for development of RLS (Ondo et al 2002). Disturbance of iron metabolism may also influence the relationships between RLS and conditions such as uremia, pregnancy, and rheumatoid arthritis.

Thus, physicians faced with a patient with RLS should inquire about factors predisposing to iron deficiency, including menorrhagia in premenopausal women, coeliac disease, gastrointestinal and urinary blood loss, and frequent blood donation. Full blood count to exclude anemia, serum ferritin and transferrin saturation, serum urea and creatinine and blood glucose should be performed, at a minimum. With symptoms or physical findings suggestive of nerve root damage or neuropathy, the patient should be evaluated for neuropathy and for factors contributing to neuropathy.

\section{Iron-dopamine hypothesis}

The improvement in RLS with dopaminergic agonists and the worsening of symptoms with dopaminergic antagonists that cross the blood-brain barrier, combined with the lack of effect of the dopamine antagonist domperidone, which does not cross the blood-brain barrier, suggest an important role for the dopamine neurotransmitter system in the central nervous system in the pathogenesis of RLS. Positron emission tomography and single photon emission computed tomography studies have found a decreased activity of the dopamine D2-receptor in the striatum in RLS, consistent with a role for a subcortical dysfunction of the dopaminergic system in RLS (Turjanski et al 1999; Michaud et al 2002).

Reflex studies suggest that RLS involves increased (rather than the normal decreased) spinal cord excitability with sleep, probably due to impaired subcortical regulation of spinal function (Bara-Jimenez et al 2000; Aksu and BaraJimenez 2002). Functional MRI studies showing activation of the thalamus and cerebellum during sensory events (without movements), and of the pons and red nucleus during sensory events that were accompanied by movements in RLS are also consistent with subcortical dysfunction (Bucher et al 1997). The dopaminergic A11 cell group is postulated as being centrally involved as they are the only neurones which provide dopaminergic axons to the spinal cord; lesions of the subcortical A11 dopamine system in rats produces increased startle response and increased locomotion, possibly suggesting the motor restlessness of RLS (Ondo, He, et al 2000).

Iron is an essential cofactor for tyrosine hydoxylase, the rate-limiting enzyme for dopamine synthesis. In animal studies, iron deficiency is associated with hypofunction of dopamine D2 receptors that is corrected by iron replacement (Erikson et al 2003; Burhans et al 2005). The fact that the established secondary causes of RLS share disturbance of iron metabolism as a common feature, that the degree of iron deficiency correlates well with symptoms, and that iron is an effective therapy, at least in iron-deficient patients provide clinical support for the importance of iron deficiency in the pathogenesis of RLS. Further support comes from cerebrospinal fluid analysis of iron indices suggesting brain iron deficiency (Earley et al 2000), and from magnetic resonance imaging (MRI) (Allen et al 2001) and autopsy findings of regional basal ganglia iron deficiency (Connor et al 2004).

Thus, the current hypothesis is that RLS involves a functional disturbance of dopamine neurotransmission in subcortical areas of the brain, provoked by regional iron deficiency or by genetic factors or both, resulting in decreased inhibition of the sensorimotor cortical system and (particularly during sleep) of the spinal system. 


\section{RLS is treatable}

\section{Non-pharmacological measures}

There are now a number of proven, effective therapies for RLS. However, the first issue for the clinician is whether or not pharmacological therapy is required. Nonpharmacological measures should be considered first in all but the most severe of cases. These included regular exercise, and improved sleep hygiene with regular sleep wake cycle and avoidance of alcohol, nicotine, and caffeine (Thorpy 2005). Patients may already have identified measures that they find helpful in preventing or ameliorating RLS symptoms. These may include physical activity such as stretching exercises just before bedtime; hot or, less often cold baths before bedtime; and mental activities that occupy them such as video games, conversation or even knitting. Nicotine, caffeine, alcohol, many antidepressants, antihistamines, most antinausea agents, and most antipsychotics have the potential to increase RLS symptoms or PLMS and should be avoided if possible.

\section{Pharmacotherapy: general principles}

Finding the best treatment for an individual patient usually proceeds in a 'hit and miss' fashion. Medications should be used at the lowest effective dose, and when necessary the dose should be titrated upward slowly. Medication should be given early enough to allow absorption and action before the onset of sleep; divided doses are often needed, most commonly with the evening meal and later at night. If the first agent does not work, then a second agent with a different mode of action should be substituted; sometimes a combination of medications works better than any single agent.

Table 3 summarizes the double-blind randomized controlled trials reported to date. Many of the initial studies were small crossover trials, and it is only in recent years that relatively large scale studies have been conducted.

\section{Dopaminergic therapy}

Akpinar's (1982) discovery that levodopa was dramatically effective in RLS revolutionized the management of RLS. Subsequently, every dopaminergic agent tested has been found to be effective against RLS and PLMS. Levodopa (with a dopa decarboxylase inhibitor) provides a remarkable near-immediate relief from RLS; this response is so characteristic that a brief trial of levodopa may be considered for patients in whom the diagnosis of RLS is in doubt (Benes et al, 1999). Levodopa is also extremely effective in haemodialysis patients with RLS (Trenkwalder et al 1995). In general, levodopa is very well tolerated. Levodopainduced dyskinesias have never been found in RLS patients. Studies with $18 \mathrm{~F}$-fluorodopa PET showing normal nigrostriatal binding capacities after more than 5 years of treatment in patients with RLS provide further confirmation of the safety of levodopa in this regard (Ruottinen et al 2000).

Unfortunately, two troublesome and common problems develop with the prolonged use of levodopa and limit the value of this otherwise almost ideal agent for RLS: rebound and augmentation. Rebound is a consequence of the short half-life of levodopa; after a while, patients start to wake up at $4 \mathrm{AM}$ or $5 \mathrm{AM}$ with recurrence of their RLS. Addition of a sustained release preparation can delay the onset of rebound until later in the morning, although the long-term efficacy of this approach is not well established (Collado-

Table 3 Medications shown to benefit idiopathic restless legs syndrome (RLS) in randomized double blind trials

\begin{tabular}{|c|c|c|}
\hline Medication & Starting - usual dose & $\begin{array}{l}\text { Evidence } \\
\text { base }\end{array}$ \\
\hline \multicolumn{3}{|c|}{ Dopamine precursors } \\
\hline $\begin{array}{l}\text { Levodopa +/- } \\
\text { benserazide }\end{array}$ & $50-200 \mathrm{mg}$ at night & $\begin{array}{l}3 \mathrm{RCTs}, \\
58 \text { pts }\end{array}$ \\
\hline $\begin{array}{l}\text { Combined slow } \\
\text { and regular release } \\
\text { levodopa }\end{array}$ & $100-200 \mathrm{mg}$ at night & $\begin{array}{l}2 \text { RCT } \\
51 \mathrm{pts}\end{array}$ \\
\hline \multicolumn{3}{|c|}{ Dopaminergic agonists } \\
\hline Pergolide & $0.025-0.5 \mathrm{mg}$ daily & $\begin{array}{l}3 \text { RCTs } \\
146 \text { pts }\end{array}$ \\
\hline Pramipexole & $0.125-1.5 \mathrm{mg}$ daily & $\begin{array}{l}2 \text { RCTs } \\
355 \text { pts }\end{array}$ \\
\hline Ropinirole & $0.25-3.0 \mathrm{mg}$ daily & $\begin{array}{l}4 \text { RCTs } \\
595 \text { pts }\end{array}$ \\
\hline Cabergoline & $0.5-2.0 \mathrm{mg}$ daily & $\begin{array}{l}\text { I RCT } \\
85 \text { pts }\end{array}$ \\
\hline Rotigotine (patch) & I. $125-4.5 \mathrm{mg}$ daily & $\begin{array}{l}\text { I RCT } \\
63 \text { pts }\end{array}$ \\
\hline \multicolumn{3}{|c|}{ Sedative-hypnotic agents } \\
\hline Clonazepam & $0.25-2 \mathrm{mg}$ at night & $\begin{array}{l}\text { I RCTs } \\
6 \text { pts }\end{array}$ \\
\hline \multicolumn{3}{|l|}{ Antiepileptic agents } \\
\hline Carbamezapine & $100-300 \mathrm{mg}$ daily & $\begin{array}{l}\text { I RCT } \\
\text { I } 74 \text { pts }\end{array}$ \\
\hline Gabapentin & $300-1500 \mathrm{mg}$ daily & $\begin{array}{l}\text { I RCTs } \\
24 \text { pts }\end{array}$ \\
\hline \multicolumn{3}{|l|}{ Opioids } \\
\hline Oxycodone & 5-20 mg daily & $\begin{array}{l}\text { I RCT } \\
\text { II pts }\end{array}$ \\
\hline
\end{tabular}

Abbreviations: $\mathrm{RCT}$, randomized controlled trials; pts, patients. 
Seidel et al 1999). Augmentation is a more serious problem. This phenomenon has a number of components: symptoms develop at an earlier time in the day; they may become more severe; there may be a reduced time at rest to onset of symptoms; finally, symptoms may develop in parts of the body that were not previously involved such as the arms. Up to $80 \%$ of patients treated with levodopa have some augmentation symptoms after a few months, and about a third have sufficiently severe symptoms that a change in therapy is required (Allen and Earley 1996). For this reason, levodopa is no longer the treatment of choice for RLS, although it remains valuable for those with only intermittently severe symptoms.

Dopamine agonists are now regarded as the first-line treatment for RLS. The non-ergot agonists pramipexole, ropinirole and rotigotine, as well as the ergot derived cabergoline and pergolide, have all been shown to benefit RLS in randomized controlled trials (Table 3).

Open label studies suggest that dopamine agonists are well tolerated in patients with severe RLS who have failed other therapies and also in those with augmentation (Stiasny, Wetter, et al 2000). However, while initial reports using pramipexole suggested that augmentation was very uncommon with this agent, a recent study of prolonged treatment has suggested levels of augmentation and tolerance of $32 \%$ and $46 \%$ respectively (Winkleman and Johnston 2004). These levels are still much lower than seen with levodopa, though they seem more likely to occur in those patients who previously developed similar problems with levodopa. Dose modification may be required if augmentation or tolerance develop, but, unlike the situation with levodopa, a change in medication is rarely needed.

The largest clinical trials to date have been conducted using ropinirole. In two 12-week multinational studies, ropinirole significantly improved RLS symptoms, associated sleep disturbance and quality of life of RLS patients and was generally well tolerated (Trenwalder et al 2004; Walters et al 2004). Augmentation was not seen during the study periods. However, the differences in symptom improvement between placebo and ropinirole did not attain the predetermined clinically significant difference. Two factors may be of relevance: a large placebo response has present in both studies and the international RLS rating scale used as a primary outcome may have been insufficiently responsive to change.

\section{Other medications}

\section{Antiepileptic agents}

Carbamazepine $100-400 \mathrm{mg}$ at night has been shown in randomized trials to be effective in relieving paresthesias and in reducing the number of attacks of RLS (Telstad et al 1984). However, side effects were very common, and, increasingly, gabapentin, which is also effective but seems better tolerated, is preferred (Garcia-Borreguero et al 2002). Antiepileptic agents may have a particular role in patients with painful paraesthesias or an underlying neuropathy. In general, RLS can be treated with much smaller dosages than are required to control seizures.

\section{Opioids}

Opioids were described as useful in the treatment of RLS by Willis. Oxycodone has been proven in a small controlled study to give symptomatic improvement and to reduce PLMS (Walters et al 1993). There is, of course, the risk of dependence with this class of medication, and they should be avoided in those with a history of addiction. Nevertheless, opioids retain a role in the treatment of particularly refractory cases of RLS (Walters et al 2001). .

\section{Benzodiazepines}

Clonazepam was effective in a double-blind crossover study of 6 RLS patients (Montagna et al 1984). It is likely that the main effect of benzodiazepines in this population is mediated by sleep promotion (Saletu et al 2001). Given the very limited evidence of benefit and the risks of sedation and falls, these agents should usually be avoided in RLS.

\section{Treatment of secondary RLS}

The management of the secondary causes of RLS involves correction of the underlying problem where possible.

Treatment of iron deficiency, with or without anemia, by oral iron supplements has been reported to improve or resolve RLS symptoms. The benefit seems most clear cut in those with almost certain iron deficiency, as indicated by a serum ferritin less than $20 \mathrm{mcg} / \mathrm{L}$. However, even those with probable iron deficiency, and a serum ferritin between $20 \mathrm{mcg} / \mathrm{L}$ and $50 \mathrm{mcg} / \mathrm{L}$ may also benefit from iron supplements; hence, the current recommendation to maintain a serum ferritin greater than $50 \mathrm{mcg} / \mathrm{L}$ in RLS patients. There seems little benefit from oral iron in those with ferritin levels more than $50 \mathrm{mcg} / \mathrm{L}$ (Davis et al 2000). Standard treatment is ferrous sulphate $325 \mathrm{mg}$ daily, with or without vitamin C, 
taken on an empty stomach. There is recent evidence that RLS and hereditary hemochromatosis can coexist (Shaughnessy et al 2005), and ferritin and transferrin saturation levels should be monitored while taking iron. Potential benefits from intravenous iron therapy, even in those without systemic iron deficiency, were suggested by a study in the 1950s (Nordlander 1953) and is currently the subject of investigations.

Randomized trials have demonstrated the efficacy of levodopa (Trenkwalder et al 1995), pergolide (Pieta et al 1998), ropinirole (Pellecchia et al 2004) and gabapentin (Thorp et al 2001) in uremic patients or in those undergoing hemodialysis. Such patients are also reported to benefit from intravenous iron therapy and from successful transplantation (Sloand et al 2004).

The treatment of RLS in pregnancy is complicated by the unsuitability of most of the available medications and nonpharmacological methods should be encouraged. Treatment of iron deficiency seems reasonable, but has never been evaluated. Lower folate levels are associated with RLS during pregnancy (Lee et al 2001). Folate supplementation is now standard advice for those planning pregnancy; compliance with this advice should be checked, and folate levels assessed if necessary.

\section{Treatment summary}

In patients with regular, troublesome RLS symptoms, a dopamine agonist is the current treatment of choice, although it should be noted that there have been few satisfactory studies comparing different treatment modalities for RLS. If dopamine agoints are poorly tolerated or ineffective, gabapentin or oxycodone should be considered. .

Levodopa is an excellent option for those with intermittent symptoms, such as during a long trip or meeting. It takes only 15 to 20 minutes to become effective, and augmentation is not a risk with infrequent use.

Gabapentin or an opioid are reasonable choices where RLS symptoms are painful or where there is coexisting peripheral neuropathy.

\section{References}

Akpinar S. 1982. Treatment of restless legs syndrome with levodopa plus benserazide. Arch Neurol, 39:739.

Allen RP, Barker PB, Wehrl F, et al. 2001. MRI measurement of brain iron in patients with restless legs syndrome. Neurology, 56:263-5.

Allen RP, Earley CJ. 1996. Augmentation of the restless legs syndrome with carbidopa/levodopa. Sleep, 19:205-13.

Allen RP, La Buda MC, Becker PM, et al. 2002. Family history study of RLS. Sleep Med, 3:S3-S7.
Allen RP, Picchietti D, Henning WA, et al. 2003. Restless legs syndrome: diagnostic criteria, special considerations, and epidemiology. A report from the restless legs syndrome diagnosis and epidemiology workshop at the National Institutes of Health. Sleep Med, 4:101-19.

Allen RP, Walters AS, Montplaisir J, et al. 2005. Restless legs syndrome prevalence and impact: REST general population study. Arch Intern Med, 165:1286-92.

Aksu M, Bara-Jimenez W. 2002. State dependent excitability changes of spinal flexor reflex in patients with restless legs syndrome secondary to chronic renal failure. Sleep Med, 3:427-30.

Banno K, Delaive K, Walld R, et al. 2000. Restless legs syndrome in 218 patients: associated disorders. Sleep Med, 1:221-9.

Bara-Jimenez W, Aksu M, Graham B, et al. 2000. Periodic limb movements in sleep: state-dependent excitability of the spinal flexor reflex. Neurology, 54:1609-16.

Benes H, Kurella B, Kummer J, et al. 1999. Rapid onset of action of levodopa in restless legs syndrome: a double-blind, randomized, multicenter, crossover trial. Sleep, 15:1073-81.

Berger K, Luedemann J, Trenkwalder C, et al. 2004. Sex and the risk of restless legs syndrome in the general population. Arch Intern Med, 164:196-202.

Bjorvatn B, Leissner L, Ulfberg J, et al. 2005. Prevalence, severity and risk factors of restless legs syndrome in the general adult population in two Scandinavian countries. Sleep Med, 6:307-12.

Bonati MT, Ferini-Strambi L, Aridon P, et al. 2003. Autosomal dominant restless legs syndrome maps on chromosome 14q. Brain, 126:148592.

Bradbury A, Evans C, Allan P, et al. 1999. What are the symptoms of varicose veins? Edinburgh vein study cross sectional population survey. $B M J, 318: 353-6$.

Brocklehurst J. 2003. Restless legs syndrome as a presenting symptom in malignant disease. Age Ageing, 32:234.

Bucher SF, Seelos KC, Oertel WH, et al. 1997. Cerebral generators involved in the pathogenesis of the restless legs syndrome. Ann Neurol, 41:639-45.

Burhans MS, Dailey C, Beard Z, et al. 2005. Iron deficiency: differential effects on monoamine transporters. Nutr Neurosci, 8:31-8.

Chen S, Ondo WG, Rao S, et al. 2004. Genomewide linkage scan identifies a novel susceptibility locus for restless legs syndrome on chromosome 9p. Am J Hum Genet, 74:876-85.

Collado-Seidel V, Kohnen R, Samtleben W, et al. 1998. Clinical and biochemical findings in uremic patients with and without restless legs syndrome. Am J Kidney Dis, 31:324-8.

Collado-Seidel V, Kazenwadel J, Wetter TC, et al. 1999. A controlled study of additional sr-L-dopa in L-dopa-responsive restless legs syndrome with late-night symptoms. Neurology, 52:285-90.

Connor JR, Wang XS, Patton SM, et al. 2004. Decreased transferrin receptor expression by neuromelanin cells in restless legs syndrome. Neurology, 62:1563-7.

Davis BJ, Rajput A, Rajput ML, et al. 2000. A randomized, double-blind placebo-controlled trial of iron in restless legs syndrome. Eur Neurol, 43:70-5.

Desautels A, Turecki G, Montplaisir J, et al. 2001. Identification of a major susceptibility locus for restless legs syndrome on chromosome 12q. Am J Hum Genet, 69:1266-70.

Dorsey CM, Lukas SE, Cunningham SL. 1996. Fluoxetine-induced sleep disturbance in depressed patients. Neuropsychopharmacology, 14:43742.

Dressler D, Thompson PD, Gledhill RF, et al. 1994. The syndrome of painful legs and moving toes. Mov Disord, 9:13-21.

Earley CJ, Connor JR, Beard JL, et al. 2000. Abnormalities in CSF concentrations of ferritin and transferrin in restless legs syndrome. Neurology, 54:1698-700.

Egan D, O'Dubhghaill C, McNamee S, et al. 2003. A community study of the prevalence of restless legs. Ir Med J, 96:153.

Ekbom KA. 1944. Asthenia Crurum Parasthetica (irritable legs). Acta Medica Scand, 118:197-8. 
Ekbom KA. 1945. Restless legs: a clinical study. Acta Medica Scand Suppl, 158:1-6

Ekbom KA. 1960. Restless legs syndrome. Neurology, 10:868-73.

Erikson KM, Jones BC, Hess EJ, et al. 2003. Iron deficiency decreases dopamine D1 and D2 receptors in rat brain. Pharmacol Biochem Behav, 69:409-18.

Garcia-Borreguero D, Odin P, Serrano C. 2003. Restless legs syndrome and PD: a review of the evidence for a possible association. Neurology, 61(Suppl 3):S49-55.

Garcia-Borreguero D, Larrosa O, de la Llave Y, et al. 2002. Treatment of restless legs syndrome with gabapentin: a double-blind, cross-over study. Neurology, 59:1573-9.

Gemignani F, Marbani A, Di Giovanni G, et al. 1999. Charcoy-MarieTooth disease type 2 with restless legs syndrome. Neurology, 52:10646.

Gudbjornsson B, Broman JE, Hetta J, et al. 1993. Sleep disturbances in patients with primary Sjogren's syndrome. Br J Rheumatol, 32:1072-6.

Hening W, Walters AS, Allen RP, et al. 2004. Impact, diagnosis and treatment of restless legs syndrome (RLS) in a primary care population: the REST (RLS epidemiology, symptoms, and treatment) primary care study. Sleep Med, 5:237-46.

Högl B, Kiechl S, Willeit J, et al. 2005. Restless legs syndrome: a community-based study of prevalence, severity, and risk factors. Neurology, 64:1920-4.

Kanter AH. 1995. The effect of sclerotherapy on restless legs syndrome. Dermatol Surg, 21:328-32.

Kim J, Choi C, Shin K, et al. 2005. Prevalence of restless legs syndrome and associated factors in the Korean adult population: the Korean Health and Genome Study. Psychiatry Clin Neurosci, 59:350-3.

Kotagal S, Silber MH. 2004. Childhood-onset restless legs syndrome. Ann Neurol, 56:803-7.

Lavigne GJ, Montplaisir JY. 1994. Restless legs syndrome and sleep bruxism: prevalence and association among Canadians. Sleep, 17:73943.

Lee KA, Zaffke ME, Baratte-Beebe K. 2001. Restless legs syndrome and sleep disturbance during pregnancy: the role of folate and iron. $J$ Womens Health Gend Based Med, 10:335-41.

Michaud M, Soucy JP, Chabli A, et al. 2002. SPECT imaging of striatal pre- and postsynaptic dopaminergic status in restless legs syndrome with periodic leg movements in sleep. J Neurol, 249:164-70.

Mizuno S, Miyaoka T, Inagaki T, et al. 2005. Prevalence of restless legs syndrome in non-institutionalized Japanese elderly. Psychiatry Clin Neurosci, 59:461-5.

Montagna P, Sassoli de Bianchi L, Zucconi M, et al. 1984. Clonazepam and vibration in restless legs syndrome. Acta Neurol Scand, 69:42830 .

Nofzinger EA, Fasiczka A, Berman S, et al. 2000. Bupropion SR reduces periodic limb movements associated with arousals from sleep in depressed patients with periodic limb movement disorder. J Clin Psychiatry, 61:858-62.

Nordlander N. 1953. Therapy in restless legs. Acta Med Scand, 45:453-7.

Ohayon MM, Roth T. 2002. Prevalence of restless legs syndrome and periodic limb movement disorder in the general population. $J$ Psychosom Res, 53:547-54.

O’Keeffe ST, Noel J, Lavan JN. 1993. Restless legs syndrome in the elderly. Postgrad Med J, 69:701-3.

O’Keeffe S, Gavin K, Lavan J. 1994. Iron status and restless legs syndrome in the elderly. Age Ageing, 23:200-3.

O'Keeffe ST. 2005. Secondary causes of restless legs syndrome in older people. Age Ageing, 34:349-52.

Ondo W, Jankovic J. 1996. Restless legs syndrome: clinicoetiologic correlates. Neurology, 47:1435-41.

Ondo WG, He Y, Rajasekaran S, Le WD. 2000. Clinical correlates of 6hydroxydopamine injections into A11 dopaminergic neurons in rats: a possible model for restless legs syndrome. Mov Disord, 15:154-8.
Ondo WG, Vuong KD, Jankovic J. 2002. Exploring the relationship between Parkinson disease and restless legs syndrome. Arch Neurol, 59:421-4.

Pellecchia MT, Vitale C, Sabatini M, et al. 2004. Ropinirole as a treatment of restless legs syndrome in patients on chronic hemodialysis: an open randomized crossover trial versus levodopa sustained release. Clin Neuropharmacol, 27:178-81.

Phillips B, Young T, Finn L, et al. 2000. Epidemiology of restless legs symptoms in adults. Arch Intern Med, 160:2137-41.

Picchietti D, Winkelman JW. 2005. Restless legs syndrome, periodic limb movements in sleep, and depression. Sleep, 28:891-8. Pieta J, Millar T, Zacharias J, et al. 1998. Effect of pergolide on restless legs and leg movements in sleep in uremic patients. Sleep, 21:61722.

Polydekis M, Allen RP, Hauer P, et al. 2000. Subclinical sensory neuropathy in late onset restless legs syndrome. Neurology, 55:1115-21.

Ruottinen HM, Partinen M, Hublin C, et al. 2000. An FDOPA PET study in patients with periodic limb movement disorder and restless legs syndrome. Neurology, 54:502-4.

Reynolds G, Blake DR, Pall HS, et al. 1986. Restless leg syndrome and rheumatoid arthritis. BMJ, 292:659-60.

Rothdach AJ, Trenkwalder C, Haberstock J, et al. 2000. Prevalence and risk factors of RLS in an elderly population: the MEMO study. Memory and Morbidity in Augsburg Elderly. Neurology, 54:1064-8.

Saletu M, Anderer P, Saletu-Zyhlarz G, et al. 2001. Restless legs syndrome (RLS) and periodic limb movement disorder (PLMD): acute placebocontrolled sleep laboratory studies with clonazepam. Eur Neuropsychopharmacol, 11:153-61.

Salih AM, Gray RE, Mills KR, et al. 1994. A clinical, serological and neurophysiological study of restless legs syndrome in rheumatoid arthritis. Br J Rheumatol, 33:60-3.

Sevim S, Dogu O, Camdeviren H, et al. 2003. Unexpectedly low prevalence and unusual characteristics of RLS in Mersin, Turkey. Neurology, 61:1562-9.

Shaughnessy P, Lee J, O'Keeffe ST. 2005. Restless legs syndrome in patients with hereditary hemochromatosis. Neurology, 64:2158.

Sloand JA, Shelly MA, Feigin A, et al 2004. A double-blind, placebocontrolled trial of intravenous iron dextran therapy in patients with ESRD and restless legs syndrome. Am J Kidney Dis, 43:663-70.

Stiasny K, Wetter TC, Trenkwalder C, et al. 2000. Restless legs syndrome and its treatment by dopamine agonists. Parkinsonism Relat Disord, 7:21-5.

Telstad W, Sorensen O, Larsen S, et al. 1984. Treatment of the restless legs syndrome with carbamazepine: a double blind study. BMJ, 288:444-6.

Thorp ML, Morris CD, Bagby SP. 2001. A crossover study of gabapentin in treatment of restless legs syndrome among hemodialysis patients. Am J Kidney Dis, 38:104-8.

Thorpy MJ. 2005. New paradigms in the treatment of restless legs syndrome. Neurology, 64(Suppl 3):S28-33.

Tison F, Crochard A, Leger D, et al. 2005. Epidemiology of restless legs syndrome in French adults: a nationwide survey: the INSTANT Study. Neurology, 65:239-46.

Trenkwalder C, Garcia-Borreguero D, Montagna P, et al. 2004. Ropinirole in the treatment of restless legs syndrome: results from the TREAT RLS 1 study, a 12 week, randomised, placebo controlled study in 10 European countries. J Neurol Neurosurg Psychiatry, 75:92-7.

Trenkwalder C, Seidel VC, Gasser T, et al. 1996. Clinical symptoms and possible anticipation in a large kindred of familial restless legs syndrome. Mov Disord, 4:389-94.

Trenkwalder C, Stiasny K, Pollmacher T, et al. 1995. L-dopa therapy of uremic and idiopathic restless legs syndrome: a double-blind, crossover trial. Sleep, 18:681-8.

Trenkwalder C, Walters AS, Hening W. 1996. Periodic limb movements and restless legs syndrome. Neurol Clin, 14:629-50. 
Turjanski N, Lees AJ, Brooks DJ. 1999. Striatal dopaminergic function in restless legs syndrome: $18 \mathrm{~F}$-dopa and $11 \mathrm{C}$-raclopride PET studies. Neurology, 52:932-7.

Ulfberg J, Nystrom B, Carter N, et al. 2001. Restless Legs Syndrome among working-aged women. Eur Neurol, 46:17-19.

Van Dijk JG, Bollen EL, Slootweg J, et al. 1991. No difference in the efficacy of hydroquinine and placebo in restless legs syndrome. Nederlands Tijdschrift Voor Geneeskunde, 135:759-63.

Walters AS, Hening WA, Rubinstein M, et al. 1991. A ckinical and polysomnographic comparison of neuroleptic-induced akathisia and idiopathic RLS. Sleep, 14:339-45.

Walters AS, Hickey K, Maltzman J, et al. 1996. A questionnaire study of 138 patients with restless legs syndrome: the 'Night-Walkers' survey. Neurology, 46:92-5.

Walters AS; International Restless Legs Study Group. 1995. Toward a better definition of the restless legs syndrome. Mov Disord, 10:634-42.

Walters AS, Ondo WG, Dreykluft T et al. 2004. Ropinirole is effective in the treatment of restless legs syndrome. TREAT RLS 2: a 12-week, double-blind, randomized, parallel-group, placebo-controlled study. Mov Disord, 19:1414-23.
Walters AS, Wagner ML, Hening WA, et al. 1993.Successful treatment of the idiopathic restless legs syndrome in a randomized double-blind trial of oxycodone versus placebo. Sleep, 16:327-32.

Walters AS, Winkelmann J, Trenkwalder C, et al. 2001. Long-term followup on restless legs syndrome patients treated with opioids. Mov Disord, 16:1105-9.

Willis T. 1685. The London practice of physick. London, England: Bassett $\&$ Cooke.

Winkelman JW, Johnston L 2004. Augmentation and tolerance with longterm pramipexole treatment of restless legs syndrome (RLS). Sleep Med, 5:9-14.

Winkelmann J. 2002. The genetics of restless legs syndrome. Sleep Med, 3:S9-12.

Winkelmann J, Prager M, Lieb R, et al. 2005. "Anxietas tibiarum". Depression and anxiety disorders in patients with restless legs syndrome. J Neurol, 252:67-71.

Woloshin S, Schwartz LM. 2006. Giving legs to restless legs: a case study of how the media helps make people sick. PLoS Med, 3:e170. 
